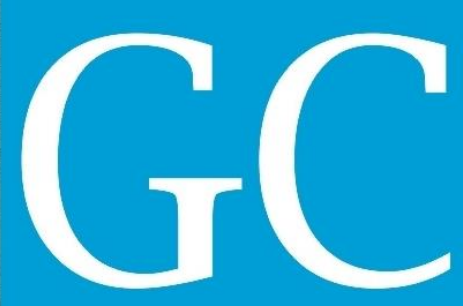

Revista Nacional de

Gerenciamento de Cidades

\title{
ANÁLISE CRÍTICA DAS CAUSAS E SOLUÇÕES SUSTENTÁVEIS PARA O CONTROLE DE ENCHENTES URBANAS: O CASO PRÁTICO DA BACIA HIDROGRÁFICA DA PRAÇA DA BANDEIRA (ESTUDO DE CASO)
}

\author{
Tania Machado Knaack de Souza ${ }^{1}$
}

Adacto Benedicto Ottoni ${ }^{2}$

\begin{abstract}
RESUMO
O crescimento urbano desordenado e as diversas atividades antrópicas impactam consideravelmente os recursos hídricos. Os mananciais originais estão cada vez mais poluídos e exauridos, afetando não só a quantidade, mas também a qualidade da água de abastecimento público. Os impactos nos recursos ambientais das bacias hidrográficas urbanas, como desmatamento das encostas, ocupação do solo sujeito a inundações, impermeabilização crescente do solo, descarte de resíduos nas encostas e nos cursos d'água, entre outras, alteram significativamente os fenômenos de origem hidrológica, agravando a formação de enchentes. As inundações podem ocasionar elevada mortalidade, em decorrência do efeito direto das enchentes e de doenças de veiculação hídrica, além dos danos ao patrimônio e transtornos ao dia a dia da cidade. Para tentar minimizar estes graves problemas socioambientais é necessária a elaboração de estudos sobre as diversas causas responsáveis pelas enchentes e de um plano de gestão global da bacia hidrográfica urbana, dentro do conceito da sustentabilidade ambiental. A proposta deste estudo foi analisar os problemas das enchentes da Bacia Hidrográfica da Praça da Bandeira, na cidade do Rio de Janeiro, através da identificação das principais causas responsáveis pelas inundações. No intuito de minimizar estes problemas, a Prefeitura anunciou a construção de obras de macrodrenagem para a região.
\end{abstract}

PALAVRAS-CHAVE: gestão de recursos hídricos, inundações, saneamento ambiental.

\section{CRITICAL ANALYSIS OF THE CAUSES AND SUSTAINABLE SOLUTIONS FOR THE URBAN FLOOD CONTROL: THE CASE STUDY OF BASIN FLAG SQUARE (CASE STUDY)}

\footnotetext{
${ }^{1}$ Engenheira Civil. Universidades Santa Úrsula e Cândido Mendes. taniaknaack@yahoo.com.br

${ }^{2}$ Engenheiro Civil Sanitarista, UERJ - Universidade do Estado do Rio de Janeiro.

adactoottoni@gmail.com
} 
Revista Nacional de

Gerenciamento de Cidades

\begin{abstract}
The urban sprawl and the various human activities significantly impact water resources. Original sources are increasingly polluted and depleted, affecting not only the quantity but also the quality of the public water supply. The impacts on environmental resources in urban watersheds, such as deforestation of the slopes, the ground subject to flooding occupation, increasing soil sealing, waste disposal on the slopes and waterways, among others, significantly alter the phenomena of hydrological origin, aggravating the formation of floods. Floods can cause high mortality, due to the direct effect of the floods and waterborne diseases, in addition to property damage and inconvenience to the daily life of the city. To try to minimize these serious environmental problems is necessary to draw up studies on the various causes responsible for floods and an overall management plan for the urban watershed, within the concept of environmental sustainability. The purpose of this study was to analyze the problems of floods Basin Flag Square in the city of Rio de Janeiro, by identifying the main causes responsible for the floods. To minimize these problems, City Hall announced the construction of macro-drainage works for the region
\end{abstract}

KEYWORDS : water management, flooding, environmental sanitation .

\title{
ANÁLISIS CRÍTICO DE LAS CAUSAS Y SOLUCIONES SOSTENIBLES PARA EL CONTROL DE INUNDACIONES URBANAS: EL CASO DE LA CUENCA INDICADOR CUADRADO (ESTUDIO DE CASO)
}

\begin{abstract}
RESUMEN
La expansión urbana y de las diversas actividades humanas impactan significativamente los recursos hídricos. Fuentes originales son cada vez más contaminado y empobrecido, que afecta no sólo la cantidad sino también la calidad del servicio publico. Los impactos sobre los recursos ambientales en cuencas urbanas, como la deforestación de las laderas, la planta sujeta a inundar la ocupación, lo que aumenta el sellado del suelo, eliminación de residuos en las laderas y canales, entre otros, alteran significativamente los fenómenos de origen hidrológico, agravando la formación de las inundaciones. Las inundaciones pueden causar alta mortalidad, debido al efecto directo de las inundaciones y las enfermedades transmitidas por el agua, además de daños a la propiedad y los inconvenientes de la vida cotidiana de la ciudad. Para tratar de minimizar estos problemas ambientales graves es necesario elaborar estudios sobre las distintas causas responsables de las inundaciones y un plan de gestión global de la cuenca urbana, dentro del concepto de la sostenibilidad ambiental. El propósito de este estudio fue analizar los problemas de inundaciones de la Cuenca Plaza de la Bandera en la Ciudad de Río de Janeiro, mediante la identificación de las principales causas responsables de las inundaciones. Para minimizar estos problemas, el Ayuntamiento anunció la construcción de obras macro-drenaje para la región.
\end{abstract}

PALABRAS CLAVE : gestión del agua, las inundaciones, el saneamiento ambiental. 


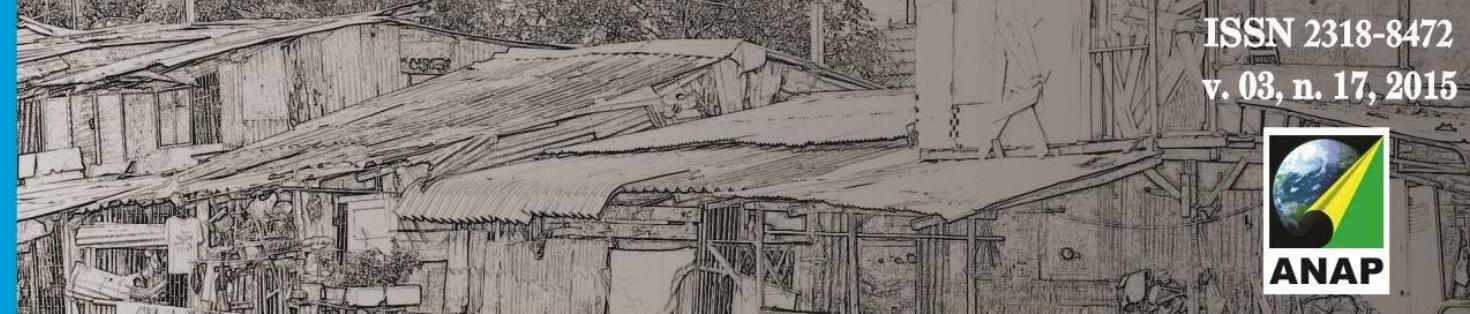

Revista Nacional de

Gerenciamento de Cidades

\section{INTRODUÇÃO}

Nas últimas décadas, a explosão demográfica e a industrialização provocaram uma urbanização acelerada, em escala mundial. No Brasil, ocorreu um processo similar: em 1950, 36,2\% da população brasileira eram urbanas, e em 2010, $84,4 \%$. (IBGE, 2010). A migração para as cidades ocorre porque elas representam oportunidades de emprego, moradia, saúde e serviços. Entretanto, o processo de urbanização sem planejamento recrudesce as desigualdades sociais, a degradação ambiental e os índices de pobreza. A falta de moradia, o desemprego crescente, e a falta de serviços básicos, geram exclusão social e problemas de saúde nos países em desenvolvimento. A grande concentração populacional, principalmente nas favelas e periferias, agrava os problemas urbanos, como a falta de serviços de saneamento básico. A ocupação sem planejamento do solo urbano tem causado sérios impactos sociais e ambientais nas metrópoles brasileiras, principalmente nos recursos hídricos.

O adensamento populacional, a ocupação urbana desordenada e as inúmeras atividades antrópicas, ocasionam uma maior impermeabilização do solo e um aumento significativo do escoamento superficial, propiciando um maior risco de enchentes. As obras imediatistas, combatendo apenas os sintomas e não as causas, a falta de políticas públicas adequadas, tendo a bacia hidrográfica como unidade de planejamento, corroboram para o agravamento do problema. A consequência de todo este descaso é um cenário recorrente e caótico de constantes e críticas enchentes, com perdas de vidas humanas, perdas de bens econômicos e proliferação de doenças de veiculação hídrica, gerando situações de calamidade pública, com prejuízos incalculáveis para a população. (TUCCI, 2005) (SEMADS, 2001).

$\mathrm{Na}$ maioria das vezes, as ações para reverter esse quadro crescente de degradação socioambiental, concentram-se apenas na tentativa de remoção dos sintomas. A complexidade intrínseca ao tema, com inúmeros fatores atuando nos 


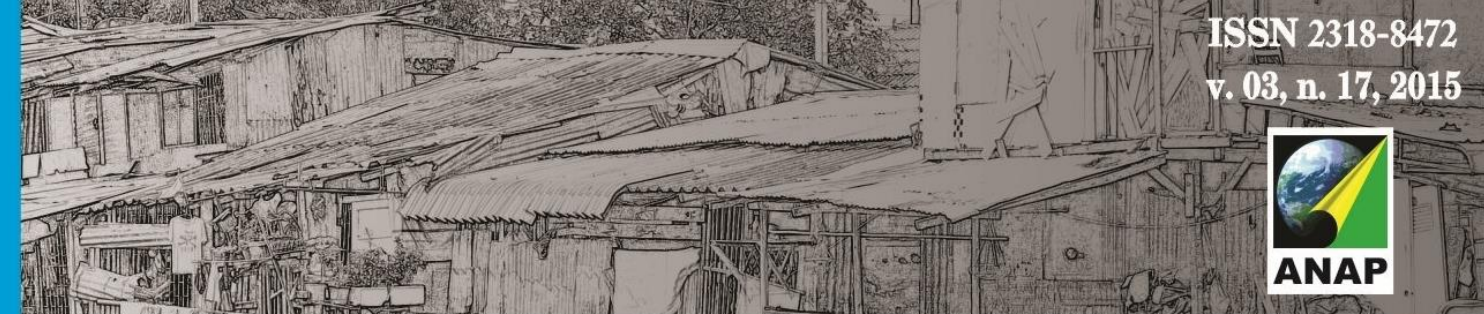

\section{Revista Nacional de}

Gerenciamento de Cidades

mais variados níveis, aponta a necessidade crescente de mais estudos, no sentido de tentar minimizar estes graves problemas socioambientais.

\section{OBJETIVOS}

O presente trabalho teve como proposta a identificação das principais causas dos problemas das enchentes numa bacia hidrográfica urbana e suas interrelações. A área de estudo escolhida foi a Bacia Hidrográfica da Praça da Bandeira. A região compõe a Praça da Bandeira, Leopoldina e o entorno do Maracanã, área muito urbanizada e foco de constantes e críticas enchentes, gerando situações de calamidade pública. No intuito de minimizar estes problemas, a Prefeitura anunciou um plano de obras de macrodrenagem para a região.

\section{METODOLOGIA}

- Diagnóstico da Bacia Hidrográfica da Praça da Bandeira;

- Avaliação das ações estruturais de controle de enchentes na Bacia Hidrográfica em estudo, entendendo a fisiografia e a rede de macrodrenagem, na região;

- Análise e discussão sobre a problemática das enchentes na bacia estudada.

\section{DRENAGEM URBANA E MEDIDAS PARA CONTROLE DE ENCHENTES}

A drenagem urbana tem como objetivo minimizar os riscos de inundações em áreas urbanas, possibilitando um desenvolvimento urbano harmônico. A sua função principal é coletar os escoamentos superficiais provenientes dos eventos 


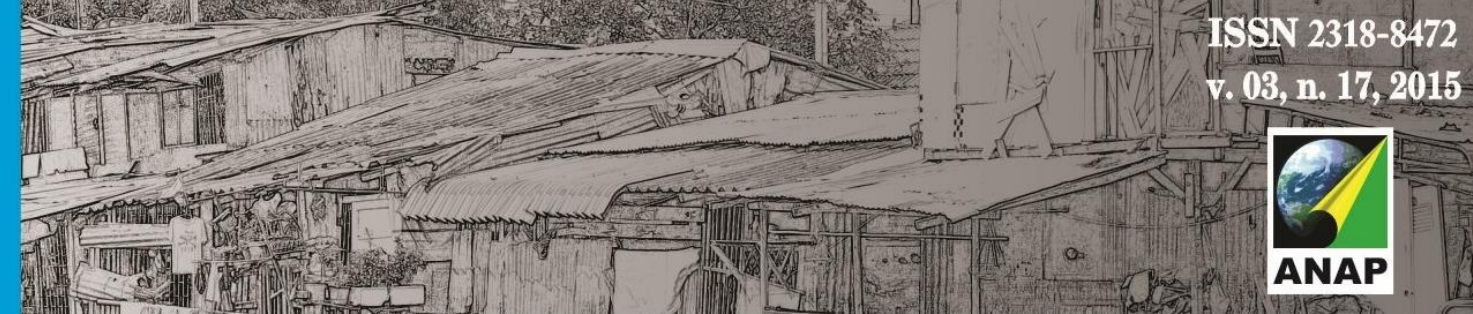

Revista Nacional de

Gerenciamento de Cidades

pluviométricos e conduzir até o destino final. $\mathrm{O}$ adensamento populacional, o grau de urbanização e os bens materiais nas áreas de risco de inundações, vão determinar as ações e medidas recomendáveis para o controle das enchentes. O conceito moderno para o controle das enchentes urbanas é a gestão sustentável das bacias hidrográficas, com uma visão global das mesmas. Mesmo quando forem necessárias obras de engenharia para proteger a população já estabelecida em áreas inundáveis, outras medidas visando à recuperação gradual do escoamento natural das águas e da regeneração da biota local devem ser implementadas, tais como: recuperação de áreas de retenção natural, recuperação e replantio da mata ciliar e reflorestamento da área da bacia, fiscalização da ocupação das margens e ao descarte de lixo, estabelecimento de política permanente para despoluição gradual das águas e ações de educação e monitoramento ambiental permanente, entre outras. (TUCCI, 2005) (SEMADS, 2001).

\section{DIAGNÓSTICO DA BACIA HIDROGRÁFICA DA PRAÇA DA BANDEIRA}

Uma das causas das enchentes da região da Praça da Bandeira tem origem no próprio processo de urbanização da cidade, com o aterramento de áreas sujeitas a inundações frequentes, como manguezais, várzeas e pântanos. O Canal do Mangue, atual corpo receptor das águas da Bacia Hidrográfica da Praça da Bandeira, surgiu com o aterramento na Baía de Guanabara para a construção do porto, o que ocasionou o desaparecimento de ilhas e o estreitamento da foz dos rios desta bacia. As enchentes na região da Praça da Bandeira ainda podem ser agravadas com a combinação de dois fatores naturais: episódios de maré cheia, quando pode ocorrer obstrução hídrica fluvial no Canal do Mangue e a ocorrência de chuvas intensas, processo pluviométrico normal do clima da cidade, ocasionando o transbordamento dos rios da região. (SEMADS, 2001). Nas figuras 1 e 2, pode-se observar fotografias de algumas destas enchentes: 


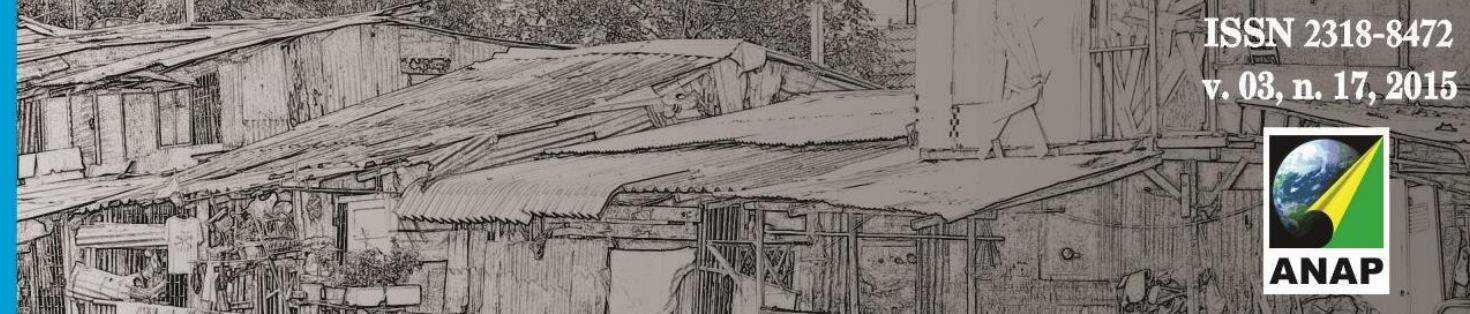

\section{Revista Nacional de}

Gerenciamento de Cidades

declividades médias superiores a $40 \%$. As altitudes máximas estão em torno de 850 metros. Apesar de grande parte desta área aclivosa ser coberta por matas densas e vegetação arbustiva com gramíneas, é também onde estão localizadas o maior número de favelas da bacia. A área de baixada da bacia, exutória das suas subbacias, é quase plana, com declividades inferiores a 2,5\%, representando cerca de $40 \%$ da área total da mesma. (GONTIJO, 2012).

Os rios da Bacia Hidrográfica da Praça da Bandeira nascem em áreas preservadas com a existência de florestas nas partes superiores da bacia drenante. No entanto, há uma crescente ocupação irregular do solo nas encostas, propiciando o desmatamento, aumento da erosão do solo e a geração de esgoto e lixo. No período de chuvas intensas há um incremento do escoamento superficial das encostas, sendo o lixo e o esgoto escoados para as calhas dos rios, aumentando o assoreamento fluvial e as vazões nas partes baixas da bacia drenante, o risco de transbordamento dos rios e consequente inundação da região urbana. A falta de rede de saneamento básico, ao longo de toda a bacia drenante, e o lançamento de esgoto in natura nas calhas dos rios aumenta a vazão nas partes baixas da bacia, contribuindo para o transbordamento de água poluída dos rios, propiciando a disseminação de doenças de veiculação hídrica, gerando um problema de saúde pública. (Figuras 3 a 5). (OTTONI et al., 2010). 


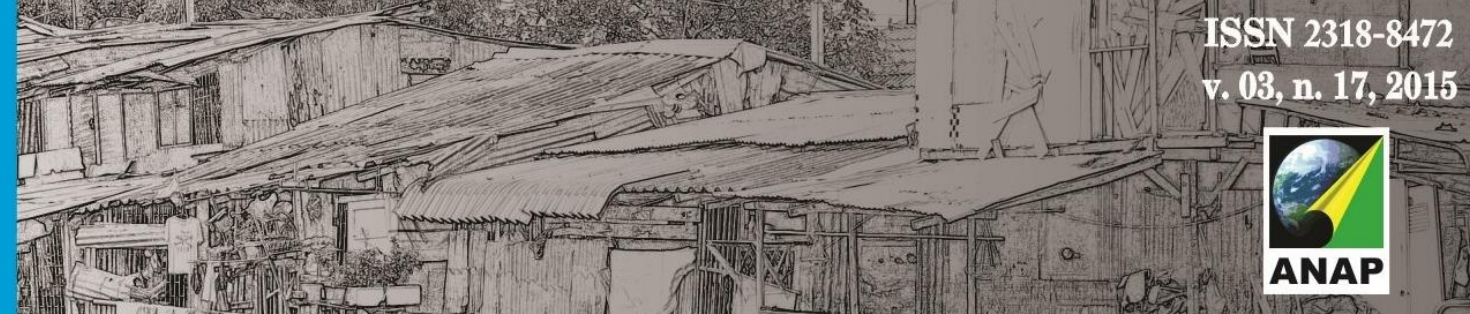

Revista Nacional de

Gerenciamento de Cidades

\section{ANÁLISE CRÍTICA DO PROJETO DE CONTROLE DE ENCHENTES DA PRAÇA DA BANDEIRA - PREFEITURA DO RIO DE JANEIRO}

No sentido de minimizar os efeitos das enchentes na região da Praça da Bandeira, a Prefeitura da Cidade do Rio de Janeiro anunciou uma série de obras de macrodrenagem nas bacias e sub-bacias drenantes. O projeto propõe uma série de intervenções para o rio Joana, considerado fator fundamental para a solução dos históricos alagamentos da região. O rio Joana nasce junto ao Pico do Andaraí Maior e, no seu trajeto atual, acompanha toda a Rua Maxwell até derivar para o rio Maracanã. (O GLOBO, 2012).

A implantação do projeto prevê o desvio de parte da vazão total do rio Maracanã para o rio Joana, na altura da Praça Varnhagem, passando pela Rua Felipe Camarão até encontrar o rio Joana. Com isso será necessário a implantação de galeria de reforço do rio Joana, aumentando a sua seção, em galeria fechada, sob a Rua Professor Manuel de Abreu, chegando até a praça, entre o Maracanã e a UERJ. Desse ponto em diante, haverá a travessia sob a linha férrea, desviando o rio Joana de seu traçado atual e fazendo-o prosseguir através de um longo túnel, que será perfurado sob os morros de São Cristóvão e da Rua Fonseca Teles. Do outro lado do túnel, o rio Joana seguirá em galeria fechada, sob a Rua São Cristóvão, até desaguar na Baía de Guanabara. (idem).

As intervenções incluem também a implantação de 04 reservatórios de grande porte. Conhecidos como "piscinões", estes reservatórios foram projetados para acumular, temporariamente, as águas de chuva durante as tempestades. E para serem esvaziados de acordo com a capacidade real da rede de drenagem, retardando o seu trajeto em direções às regiões mais baixas e, assim, impedindo transbordamentos e alagamentos. (idem). 


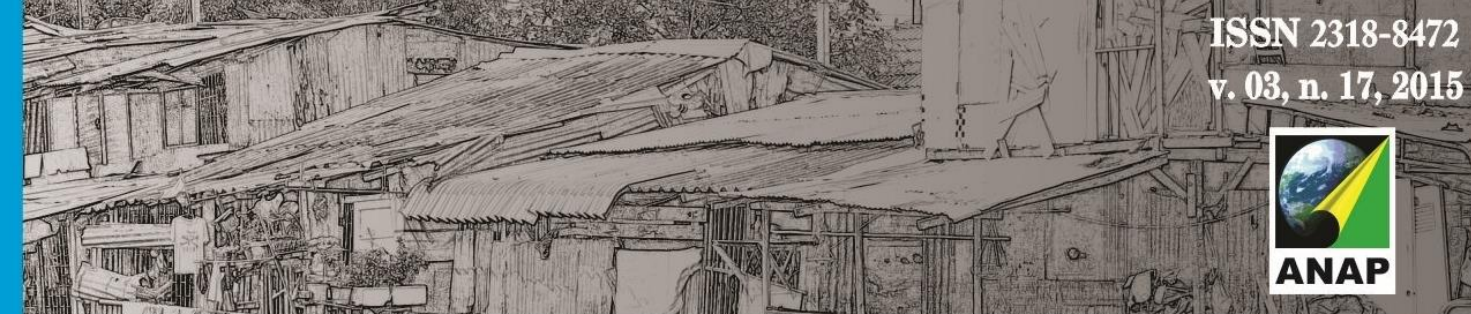

Revista Nacional de

Gerenciamento de Cidades

De acordo com KNAACK (2012), as intervenções estruturais, previstas no plano de obras da prefeitura, são importantes e visam à proteção da população da região da Praça da Bandeira e seu entorno, tais como, o extravasor do rio Maracanã para o rio Joana e o desvio do rio Joana para deságue na Baía de Guanabara. Mas, as medidas propostas combatem apenas as consequências das enchentes e não as suas causas. Elas deveriam vir acopladas a medidas complementares, dentro do conceito da sustentabilidade socioambiental, tais como o manejo hídrico adequado das águas de chuva ao longo de toda a bacia urbana, monitoramento ambiental permanente e programas visando à melhoria das condições sanitárias ao longo da bacia hidrográfica, gerando novos postos de trabalho e propiciando capacitação profissional para a população carente local. As intervenções nas bacias devem ser voltadas para tentar recriar, o máximo possível, o estado natural do meio ambiente. Normalmente, em áreas urbanizadas torna-se necessário a adoção de obras de engenharia, mais impactantes, para a proteção da população já assentada em áreas inundáveis. No entanto, estas obras devem vir sempre acompanhadas de medidas complementares, visando à gestão socioambiental da bacia hidrográfica. Como caso real, temos a cidade de São Paulo onde foram construídos vários piscinões sem a adoção de medidas complementares. O resultado observado é a ineficácia do projeto, com a continuidade de inundações de grandes proporções na capital paulistana.

A seguir, são apresentados os problemas mais relevantes observados na análise do projeto:

- A falta de um programa de coleta de esgotos sanitários ao longo da bacia hidrográfica com a gradual despoluição das águas fluviais. Os rios estudados recebem uma quantidade, constante e significativa, de esgoto bruto, através de vários pontos de lançamento, aumentando muito a sua vazão natural, contribuindo para o assoreamento hídrico e a poluição fluvial, e potencializando o risco de inundações; 


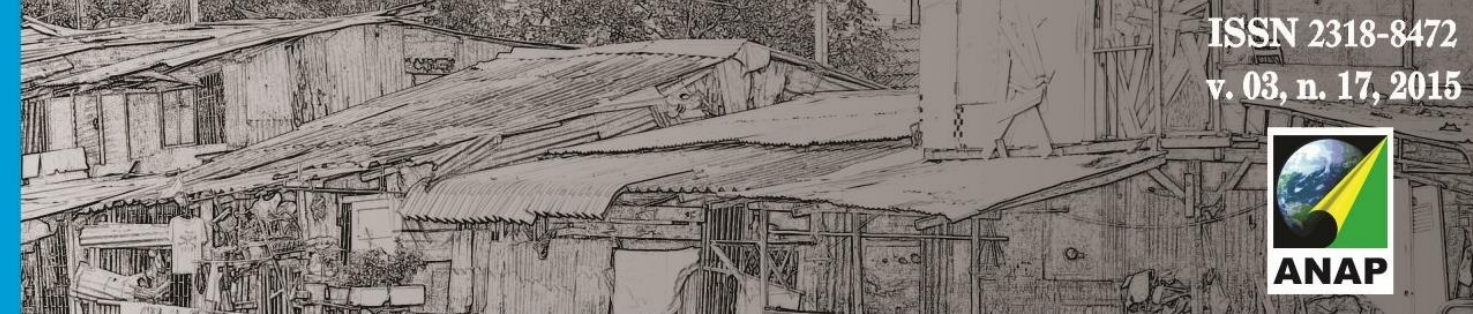

\section{Revista Nacional de}

Gerenciamento de Cidades

- Os reservatórios de detenção não funcionarão como reservatórios de água de chuva (provenientes do escoamento superficial hídrico do solo urbano), e sim como reservatórios de transbordo da água poluída dos rios. Os locais poderão se tornar um local de criação de vetores, um problema de saúde pública, com a disseminação de inúmeras doenças de veiculação hídrica. Com a quantidade enorme de lixo lançado nos rios, também há o risco de entupimento das grades na entrada dos reservatórios, podendo causar novas manchas de inundação em áreas que antes não sofriam enchentes, pelo possível desvio das águas que estariam sendo encaminhadas aos referidos piscinões;

- A falta de um programa representativo de coleta seletiva e de reciclagem do lixo. E concomitante a este projeto, um programa de capacitação/educação ambiental para a população carente local;

- Não há previsão de um programa efetivo e representativo de recuperação e replantio da mata ciliar e da vegetação das encostas;

- Não há previsão de um programa de recuperação de áreas de retenção natural;

- Carência de obras de regularização/correção das singularidades hidráulicas no leito dos rios, na parte baixa da bacia, que reduzem a seção de escoamento, podendo agravar as inundações, tais como: seções de ponte, curvas íngremes e trechos onde o escoamento está sob o arruamento, o que gera bolsões que diminuem a capacidade de escoamento e aumenta o risco de transbordamento do rio.

\section{CONCLUSÕES E RECOMENDAÇÕES:}

Como sugestões de ações para prevenção e mitigação do efeito das enchentes na Bacia Hidrográfica da Praça da Bandeira, podemos citar: 


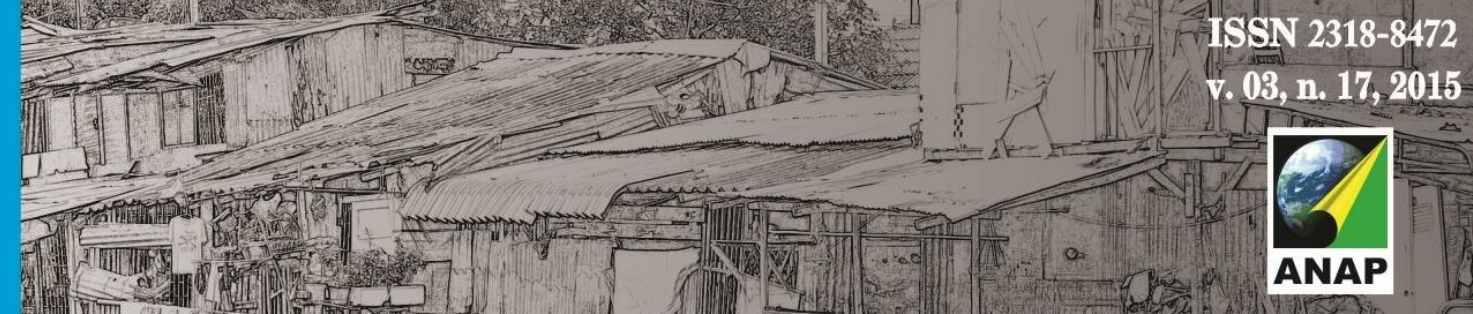

\section{Revista Nacional de}

Gerenciamento de Cidades

lançado nos rios aumenta 0 assoreamento fluvial e 0 risco de transbordamento do mesmo nas épocas de chuvas intensas.

- Obras de regularização/correção para minimizar as perdas de cargas do escoamento, que elevam o nível d'água e aumentam o risco de transbordamento do rio. Como exemplo, podemos citar: estreitamento de calha por pilar de ponte, curvas acentuadas do leito dos rios, e trechos onde $o$ escoamento está sob o arruamento.

- Construção de pequenos e médios reservatórios de cheias nos trechos médio e superior dos rios, visando reter volume considerável de água de chuva, reduzindo a vazão de escoamento e os riscos de transbordamento dos rios nas áreas críticas, como Praça da Bandeira e arredores. Esses reservatórios de cheia funcionam como pequenas barragens construídas nas calhas dos rios para controle da inundação. A altura da barragem e o diâmetro do orifício, localizado na parte baixa da barragem, são dimensionados de forma a permitir uma vazão efluente para que não haja transbordamento do rio a jusante.

- Implantação de bacias de detenção, adequadamente localizadas (normalmente em cota inferior ao arruamento) em áreas de lazer, parques públicos, campos de futebol e áreas similares, com o objetivo de reter escoamentos da rede de esgotos pluviais, durante os períodos de chuvas intensas. Estas bacias correspondem a áreas de reservação de escoamento superficial, ligadas ao sistema de drenagem urbana, de preferência, por gravidade, através de um orifício localizado em sua parte inferior. A construção de várias bacias de detenção, estrategicamente localizadas, reduziria significativamente o aporte de escoamento para o leito dos rios, diminuindo a possibilidade de transbordamento dos mesmos e da inundação da região da Praça da Bandeira. 


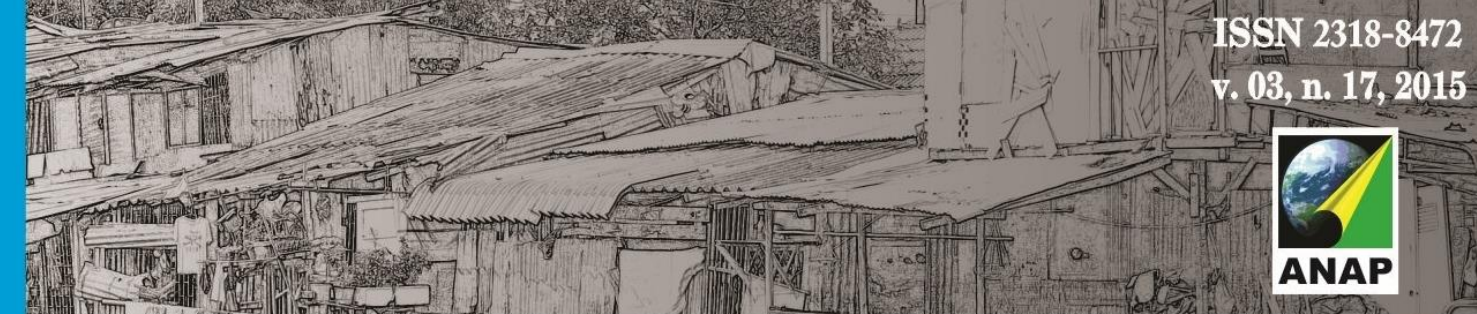

\section{Revista Nacional de}

Gerenciamento de Cidades

- Implantação de monitoramento hidrométrico e de qualidade da água dos rios da bacia hidrográfica, visando o registro e a análise mais precisa da necessidade de medidas de controle de poluição e de controle de enchentes.

- Limpeza e desobstrução permanente das calhas dos leitos dos rios e dos canais de drenagem, principalmente nos períodos chuvosos.

- Implantação de monitoramento por georeferenciamento permanente nas áreas críticas locais, visando a proteção ambiental da região e o controle das ocupações irregulares responsáveis pelo desmatamento, deslizamentos de encostas, erosão do solo, entre outros.

- Reavaliação e revisão constante do sistema de drenagem pluvial, procurando-se constatar se está apropriada às condições atuais de uso e ocupação do solo.

\section{REFERÊNCIAS BIBLIOGRÁFICAS}

GONTIJO A, A história dos rios Tijucanos - Parte I. Instituto Eventos Ambientais; 2012. [capturado 10 jan. 2012]. Disponível em: http://www.ieva.org.br/

IBGE. Censo demográfico 20. Rio de Janeiro: Instituto Brasileiro de Geografia e Estatística. IBGE, 2010.

KNAACK, T. S. Análise crítica das causas e soluções sustentáveis para o controle de enchentes urbanas: o caso prático da Bacia Hidrográfica da Praça da Bandeira. Especialização em Engenharia Sanitária e Ambiental. ENSP, FIOCRUZ. Rio de Janeiro. 2012.

MMA. Cidades sustentáveis: subsídios à elaboração da Agenda 21 Brasileira. Brasília: Ministério de Meio Ambiente. 2000. 155p.

O GLOBO, Projeto de controle de enchentes da Praça da Bandeira. Rio de Janeiro, 2012. [capturado 27 nov. 2012]. Disponível em: http://oglobo.globo.com/videos/t/todos-os-videos/v/catalogo/1784254

OTTONI, Adacto, DESTRI, Amauri, ARAÚJO, Miguel -_Diagnóstico Preliminar e Sugestões de Soluções com Sustentabilidade Ambiental para as Enchentes Ocorridas na Praça da Bandeira com as Chuvas de Abril/2010 - UERJ - Rio de Janeiro - 2010.

PROSAB Manejo de Aguas Pluviais Urbanas/ Antonio Marozzi Righetto (coordenador). Rio de Janeiro: ABES, 2009. 396p.: ilProjeto PROSAB

RIOÁGUAS - Maracanã e Praça da Bandeira - Controle de Enchentes na Bacia do Canal do Mangue Fundação RioÁguas - 2011 


\section{Revista Nacional de}

Gerenciamento de Cidades

SEMADS. Enchentes no Estado do Rio de Janeiro - Uma Abordagem Geral - Rio de Janeiro. Secretaria de Meio Ambiente e Desenvolvimento Sustentável. Cooperação Técnica Brasil-Alemanha. Projeto PLANÁGUA-SEMADS/GTZ. 2001. 160p.

TUCCI, C. E. M. Gestão de Águas Pluviais Urbanas - Ministério das Cidades - Global Water Partnership Wolrd Bank - Unesco 2005.

Águas Urbanas - Estudos Avançados 22 (63), 2008

TUCCI, C. E. M. et al. Hidrologia: ciência e aplicação. 4 ed. Porto Alegre. Editora UFRGS. 2009. 